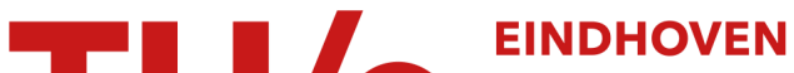 \\ UNIVERSITY OF \\ TECHNOLOGY
}

\section{High data-rate video broadcasting over $3 G$ wireless systems}

Citation for published version (APA):

Atici, C., \& Sunay, M. O. (2007). High data-rate video broadcasting over 3G wireless systems. IEEE

Transactions on Broadcasting, 53(1:2), 212-223. https://doi.org/10.1109/TBC.2007.891704

DOI:

10.1109/TBC.2007.891704

Document status and date:

Published: 01/01/2007

\section{Document Version:}

Publisher's PDF, also known as Version of Record (includes final page, issue and volume numbers)

\section{Please check the document version of this publication:}

- A submitted manuscript is the version of the article upon submission and before peer-review. There can be important differences between the submitted version and the official published version of record. People interested in the research are advised to contact the author for the final version of the publication, or visit the $\mathrm{DOI}$ to the publisher's website.

- The final author version and the galley proof are versions of the publication after peer review.

- The final published version features the final layout of the paper including the volume, issue and page numbers.

Link to publication

\section{General rights}

Copyright and moral rights for the publications made accessible in the public portal are retained by the authors and/or other copyright owners and it is a condition of accessing publications that users recognise and abide by the legal requirements associated with these rights.

- Users may download and print one copy of any publication from the public portal for the purpose of private study or research.

- You may not further distribute the material or use it for any profit-making activity or commercial gain

- You may freely distribute the URL identifying the publication in the public portal.

If the publication is distributed under the terms of Article 25fa of the Dutch Copyright Act, indicated by the "Taverne" license above, please follow below link for the End User Agreement:

www.tue.nl/taverne

Take down policy

If you believe that this document breaches copyright please contact us at:

openaccess@tue.nl

providing details and we will investigate your claim. 


\title{
High Data-Rate Video Broadcasting Over 3G Wireless Systems
}

\author{
Çağdaş Atıcı, Student Member, IEEE, and M. Oğuz Sunay, Senior Member, IEEE
}

\begin{abstract}
In cellular environments, video broadcasting is a challenging problem in which the number of users receiving the service and the average successfully decoded video data-rate have to be intelligently optimized. When video is broadcasted using the $3 G$ packet data standard, 1xEV-DO, the code space may be divided among the multiple layers if scalable video coding is employed. In this paper, we propose a novel, multi-objective optimized video broadcasting scheme for $1 \mathrm{xEV}$-DO and investigate the feasibility of using multiple layers for transmission. The multi-objective optimization aims to find the best compromise between maximizing the average decodable video data-rate and minimizing the basic quality video outage probability. Simulations conducted for the ITU Pedestrian A and Vehicular B channels show that high data-rates with low outages are possible when 1xEV-DO is used for video broadcasting, however, it may not be desirable to use scalable video coding for this purpose.
\end{abstract}

Index Terms-Broadcasting, code division multiaccess, mobile communication, resource management, video coding.

\section{INTRODUCTION}

$\mathbf{F}$ OLLOWING the rapid growth of wireless networks and the success of Internet video, wireless video services are expected to be widely deployed in the near future. Of such services, wireless video broadcasting has gained significant attention recently thanks to two highly publicized proposals: DVB-H [1] and Media-Flo [2]. Two classes of solutions exist for wireless video broadcasting, namely, high and low power solutions. The two above mentioned proposals both require transmission powers much greater than those used in today's $2 \mathrm{G}$ and $3 \mathrm{G}$ wireless systems. Subsequently, these proposals require the deployment of brand new cellular networks where cell sizes are much larger than those currently in use (tens of kilometers of cell radii). Both DVB-H and Media-Flo champion the use of OFDM over the available wide bandwidth with QPSK or 16-QAM modulation within each sub-carrier. While DVB-H uses convolutional codes, Media-Flo uses Turbo and Reed-Solomon codes for error correction.

Alternatively, one can provide a low-power, lower bandwidth video broadcasting solution using the existing $3 \mathrm{G}$ wireless network infrastructure. Evolutions, such as 1xEV-DO (IS-856) [3],

Manuscript received July 9, 2006; revised November 11, 2006. This work was supported by TÜBİTAK Career Grant 104E063.

The authors are with the Department of Electrical and Computer Engineering, Koç University, Rumeli Feneri Yolu, Sarı yer 34450 İstanbul, Turkey (e-mail: catici@ku.edu.tr; osunay@ku.edu.tr).

Color versions of one or more of the figures in this paper are available online at http://ieeexplore.ieee.org.

Digital Object Identifier 10.1109/TBC.2007.891704
1xEV-DV [4] and HSDPA [5] to the 3G standards provide spectrally efficient data services. In these systems, adaptive coding and modulation is used to accommodate for the variations in the wireless channel conditions. This paper is concerned with providing a novel, low-power video broadcasting solution using the $1 \mathrm{xEV}-\mathrm{DO}$ system. No hardware changes to the standard are required in the proposed solution. Furthermore, the existing cellular layout can be used without any modifications.

The existing 3G systems are originally designed to provide user-specific data to multiple users simultaneously. The wireless broadcast service on the other hand, is aimed to transmit the same data to all (or a sub-group of paid) customers. A conventional approach would be to guarantee every user within the coverage area the reception and successful decoding of the transmitted information by limiting the transmission data-rate to the channel capacity of the worst user. However, such an approach may under-utilize better channels in the system, and thus may be spectrally inefficient. In order to take advantage of the variations in the channel conditions of the users, it may be preferable to divide the data to be transmitted into a number of parallel streams, and subsequently guarantee a certain data-rate to all users via a base layer, while sending the rest of the information via a number of enhancement layers in such a way that only users with better channel conditions are able to receive and decode them. This way, different users perceive the broadcast video signal at different quality levels but the basic quality reception is possible for all users. This solution requires the use of a multi-layered (scalable) video source coding scheme. Scalable video coding (SVC) produces a compressed bit-stream which is divided into embedded sub-streams that can be decoded to produce video with improved quality, or larger frame rate, or larger image size depending on the source coding algorithm in use [6]. Both the ITU H.26x family of coders and the MPEG coders provide some scalability using a layered approach [7]. The layered scalable options include temporal, spatial and PSNR (quality) scalability.

When scalable video coding is employed in wireless video broadcasting, clearly one has to ensure that the base layer is successfully decoded by all of the subscribers since the base layer is independently coded and is necessary for basic quality video reception as well as possible subsequent decoding of the enhancement layers. In other words, the base layer decodability is the necessary requirement for the broadcast coverage. At the same time, the system should also be designed such that enhancement layers are successfully decoded by as many users as possible so that the average perceived service quality is maximized. This is illustrated for a cellular scenario in Fig. 1, where users that are closest to the base station are able to decode the base layer as 


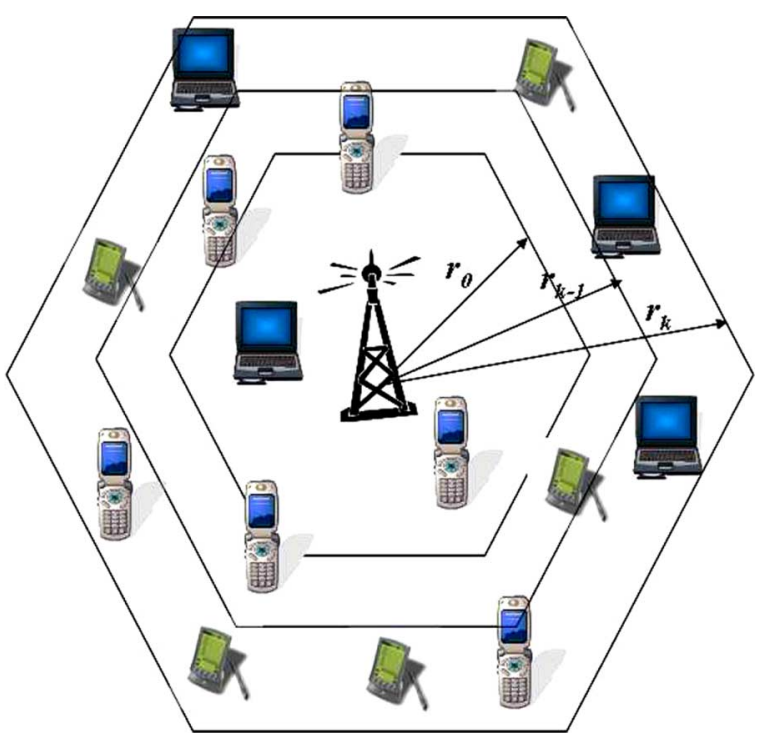

Fig. 1. Illustration of coverage distances for decodable sub-streams of the video signal.

well as all $k$ enhancement layers, while the users that are near the cell boundary can only decode the base layer. Then, the limited physical layer resources of the wireless system need to be divided among the multiple layers of the broadcast video in such a way that both of the above stated goals are achieved simultaneously.

However, from an application perspective, scalable coding may not be so desirable in a wireless scenario. This is because, if the base layer data-rate is set to be sufficient for an acceptable video quality, the additional benefit from the decoding of enhancement layers may not be significant enough to grant any allocation of system resources for them. If on the other hand, the base layer data-rate is not sufficient for acceptable video quality, then stationary users capable of decoding only the base layer will not tolerate this service and thus not use it. The practical benefit of scalable video coding in wireless systems may arise from its potential support for user mobility. Users with high mobility experience rapid variations in their channel conditions. In such instances, unlike non-scalable coding, where the users either receive the full video stream successfully or nothing at all, scalable video coding may potentially allow for a graceful variation in the observed video quality over time. However, this may be desirable only if significant outage probabilities are not observed as a result of it. In this paper we provide a feasibility study of the transmission of broadcast video using multiple layers in wireless cellular systems using 1xEV-DO.

When SVC is employed for broadcast video coding, the wireless system resources of bandwidth, power, time and code need to be efficiently divided among the layers. A number of research results have appeared in the literature on this front. In [8] the authors propose to use unequal error control protection of the SVC layers using rate-compatible punctured convolutional codes. The authors in [9] investigate an on-demand video scenario and the video stream to be transmitted is divided into two distinct layers. Based on the ARQ feedback from the users regarding the success of decoding of video packets, the base layer packets are placed at the front of the transmission queue for retransmission. The enhancement layer packets are re-transmitted only if they do not expire during their wait at the transmission queue. In [10], the authors propose to adopt the resource allocation as well as the bit rates of the individual SVC layers based on the changes in the channel conditions for an on-demand video application. The authors propose to use joint source and channel coding so that the base layer and the enhancement layers are channel coded and subsequently multilevel modulated using different parameters in [11] and [12]. The modulation parameters are chosen such that the system provides a significantly stronger error correction capability to the base layer when compared to the enhancement layers. The authors in [11] further propose the use of user feedback to adapt these parameters to changing channel characteristics, user QoS requests and terminal capabilities for on-demand video applications. In [13], the authors characterize the wireless channel using a simple random error model and determine the average broadcast video quality when unequal erasure protection is applied using Reed-Solomon codes. In [14], the transmission power is divided unequally among the layers. Naturally, the base layer is given a larger power allocation than the enhancement layers. [15] on the other hand, proposes to divide the system resources adaptively across multiple video streams based on video content and source coding specifics without paying any attention to the wireless channel.

In all of papers mentioned above, the division of system resources is done heuristically. In other words, the authors propose to use a pre-determined set of coding, modulation schemes or an unequal power division rule, and compare the performance of their choice relative to a scheme where there is no layeredcoding. The papers do not explicitly specify why such division of resources is proposed and whether it is optimal in any way.

This work differentiates itself from the rest on two fronts. First, here we propose a wireless video broadcasting scheme where the division of resources among the layers of the broadcast video is due to the optimal compromise among the two goals of the system: maximization of the base layer broadcast video coverage and maximization of average total bit-rate decoded by the users, which is proportional to the perceived video quality measured in PSNR [16]. Second, in this paper we propose to divide the system resources in the code domain. This way, it is possible to use the same modulation and channel coding schemes to all layers, simplifying the overall hardware design as well as decoding and demodulation complexity. We focus on the problem of providing broadcast video capability to an existing $3 \mathrm{G}$ system rather than developing a new end-to-end high power solution like Media-Flo or DVB-H. For a given number of SVC layers, the proposed framework provides the corresponding set of data-rates for each layer as well as the code space division for the optimal compromise.

The rest of this paper is organized as follows: A brief 1xEV-DO overview and formulation of the desired objectives used in the resource allocation are given in Section II. Multiple objective optimization is given in Section III as a framework to find the optimal compromise between multiple objectives. The wireless system model and simulation results of the proposed video broadcast scheme are presented in Section IV. Finally, conclusions are drawn in Section V. 


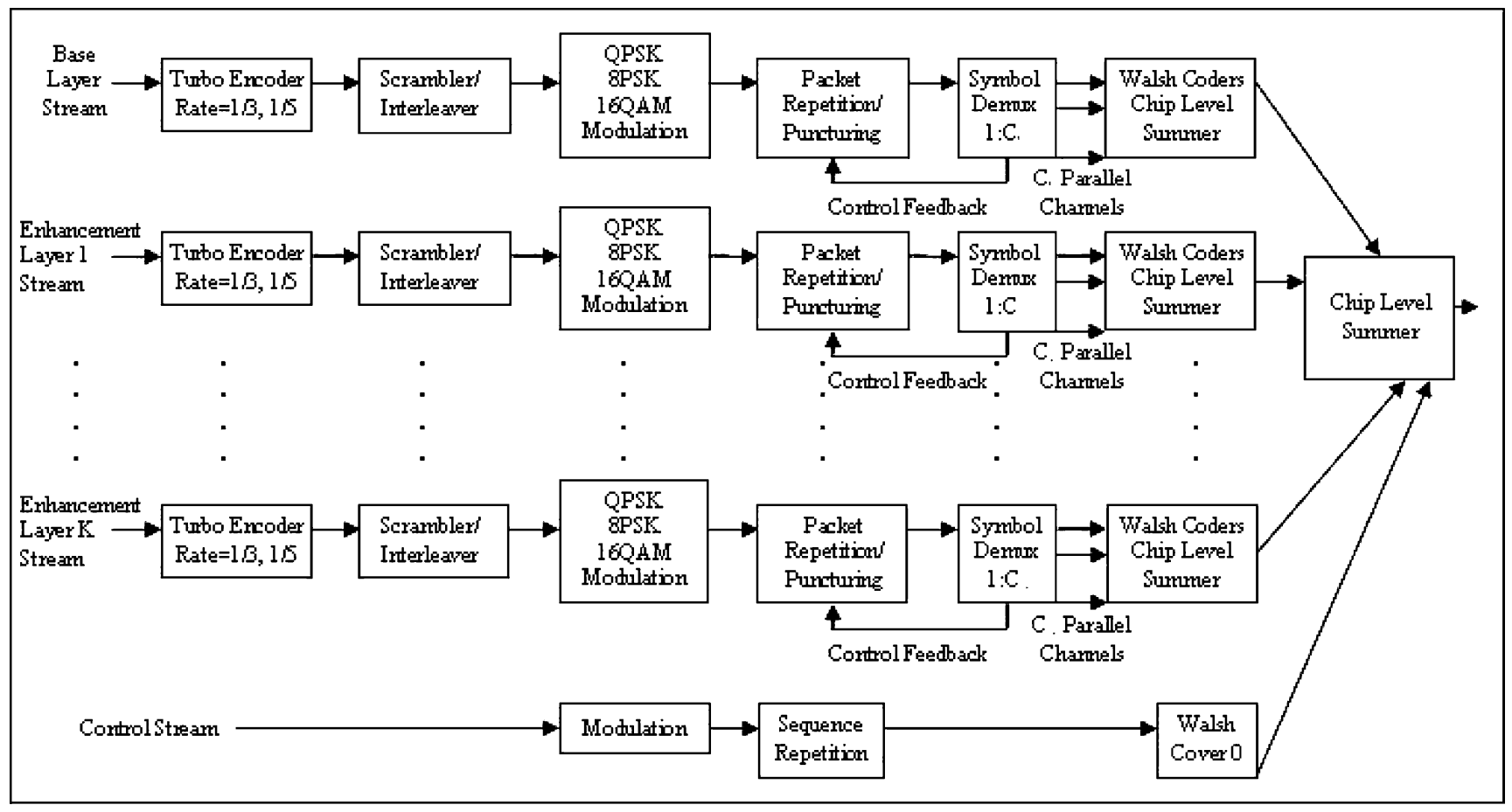

Fig. 2. Forward broadcast traffic channel structure using SVC.

\section{THE $1 \mathrm{xEV}$-DO SySTEM AND PROBLEM FoRMULATION}

The proposed low-power broadcast video solution is based on $1 \mathrm{xEV}-\mathrm{DO}$. In this section we first provide a brief overview of this air interface. 1xEV-DO (IS-856) is a data only evolution to the cdma2000 standard. It is originally designed to provide packet switched data to multiple users simultaneously. Over a bandwidth of $1.25 \mathrm{MHz}$, it provides service to only a single user at a given time. The active user is chosen according to a scheduling algorithm. Transmission is then performed over time slots of $1.67 \mathrm{~ms}$ duration. The data-rate of the active user is selected according to its observed channel conditions. In the standard, there are 12 transmission schemes with 9 distinct data-rates, ranging from $38.4 \mathrm{kbps}$ to $2.4576 \mathrm{Mbps}$ [3]. $1 \times E V-D O$ uses rate $1 / 3$ and rate $1 / 5$ Turbo codes and QPSK, 8-PSK and 16-QAM modulation schemes adaptively for transmission. Also, repetition and puncturing provide finer grain coding. After scrambling, modulation and repetition, the transmission packet is de-multiplexed into 16 blocks. Then each of these blocks is spread using one of the 16 orthogonal Walsh codes. The spread transmission packet, which has the same length of the original packet, is the summation of the 16 blocks. On the receiver side, the original information packet is recreated by de-spreading the received packet with the same Walsh codes. It should be noted here that the information bits are spread entirely by means of the error control coding in 1xEV-DO and Walsh code spreading does not cause any further increase in the transmission bandwidth. This is in line with the optimal coding-spreading trade-off discussed in [17] for a system using matched filter receivers since the system transmits to only one user at a given time and thus, does not need multiple accessing in the code domain to separate different transmitted signals.
When $1 \mathrm{xEV}-\mathrm{DO}$ is used to broadcast a video stream that is scalable coded, the above mentioned 16 Walsh codes need to be divided optimally among the different layers of the stream. The proposed division of the Walsh codes of the 1xEV-DO system is illustrated in Fig. 2. Since multiple streams are code division multiplexed, one needs to make room for CDMA spreading by reducing the repetition coding rate. However, the reduction in the coding should not result in the effective coding rate, described as,

$$
\text { Effective Code Rate }=\frac{\text { Turbo Code Rate }}{\text { Repetition Factor }}
$$

to be greater than 1 , since this would mean losing some of the information bits prior to transmission. The reduction of the repetition factor as a function of the number of Walsh codes available per layer is tabulated in Table I for $1 x E V-D O$. From the table, it is clear that not all data-rates are supportable by all code space allocations. Let us consider, for example the $307.2 \mathrm{kbps}$ transmission rate that uses rate $1 / 3$ Turbo coding. When 2 Walsh codes are available, the repetition factor in the system needs to be 0.25 , resulting in an effective coding rate of $4 / 3$ which is not feasible for effective data transmission.

In this paper, we optimally find the set of transmission datarates and the corresponding code space division for a given number of SVC layers to find the best compromise between the maximum broadcast base layer service coverage and average decodable video data-rate. There is a direct relationship between the transmission data-rate and the PSNR of the received video given a fixed packet error rate. This relationship is dependent on the nature of the source coding algorithm and the error correction and concealment techniques in use. In this paper we attempt to optimize the average received video date-rate per user 
TABLE I

REPETITION FACTOR AS A FunCtion OF AVAILABLE WALSH CODES FOR TRANSMisSiON

\begin{tabular}{|c|c|c|c|c|c|c|c|c|c|c|c|c|c|c|c|c|}
\hline & & \multicolumn{15}{|c|}{ Repetition Factor for the Available Number of Walsh Codes } \\
\hline Data-Rate & Turbo Code Rate & 16 & 14 & 13 & 12 & 11 & 10 & 9 & 8 & 7 & 6 & 5 & 4 & 3 & 2 & 1 \\
\hline 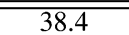 & $\overline{11 / 5}$ & $\overline{99.6}$ & $\overline{8.4}$ & $\overline{\overline{7.8}}$ & $\overline{7.2}$ & 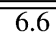 & 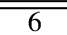 & $\overline{5.4}$ & "4.8 & 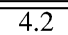 & 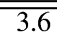 & $\overline{3}$ & 2.4 & 1.8 & 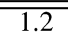 & 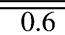 \\
\hline 76.8 & $1 / 5$ & 4.8 & 4.2 & 3.9 & 3.6 & 3.3 & 3 & 2.7 & 2.4 & 2.1 & 1.8 & 1.5 & 1.2 & 0.9 & 0.6 & 0.3 \\
\hline 153.6 & $1 / 5$ & 2.4 & 2.1 & 1.95 & 1.8 & 1.65 & 1.5 & 1.35 & 1.2 & 1.05 & 0.9 & 0.75 & 0.6 & 0.45 & 0.3 & 0.15 \\
\hline 307.2 & $1 / 3$ & 2 & 1.75 & 1.63 & 1.5 & 1.38 & 1.25 & 1.13 & 1 & 0.88 & 0.75 & 0.63 & 0.5 & 0.38 & 0.25 & 0.13 \\
\hline 614.4 & $1 / 3$ & 1 & 0.88 & 0.81 & 0.75 & 0.69 & 0.63 & 0.56 & 0.5 & 0.44 & 0.38 & 0.31 & 0.25 & 0.19 & 0.13 & 0.06 \\
\hline 921.6 & $1 / 3$ & 1 & 0.88 & 0.81 & 0.75 & 0.69 & 0.63 & 0.56 & 0.5 & 0.44 & 0.38 & 0.31 & 0.25 & 0.19 & 0.13 & 0.06 \\
\hline 1228.8 & $1 / 3$ & 1 & 0.88 & 0.81 & 0.75 & 0.69 & 0.63 & 0.56 & 0.5 & 0.44 & 0.38 & 0.31 & 0.25 & 0.19 & 0.13 & 0.06 \\
\hline 1843.2 & $1 / 3$ & 0.5 & 0.44 & 0.41 & 0.38 & 0.34 & 0.31 & 0.28 & 0.25 & 0.22 & 0.19 & 0.16 & 0.13 & 0.09 & 0.06 & 0.03 \\
\hline 2457.6 & $1 / 3$ & 0.5 & 0.44 & 0.41 & 0.38 & 0.34 & 0.31 & 0.28 & 0.25 & 0.22 & 0.19 & 0.16 & 0.13 & 0.09 & 0.06 & 0.03 \\
\hline
\end{tabular}

and calculate the corresponding PSNR values for a system that uses PSNR-scalable SVC.

In a wireless broadcast system that uses SVC, the number of users receiving different levels of quality of service depends heavily on the positions of the users over geography as well as their mobility. Since the wireless channel is prone to path loss, shadowing and multi-path fading effects, the system resources need to be carefully managed for efficient service provisioning. For a satisfactory wireless broadcast video service that uses SVC, the number of users capable of decoding at least the base layer and the average observed video quality across users need to be jointly maximized. However, when the system has limited resources these two objectives are contradictory. This is because, when more of the resources are allocated for the transmission of the base layer, fewer resources are left for the transmission of enhancement layers. This results in fewer number of users capable of decoding them successfully, reducing the overall average observed video quality. On the other hand, if fewer resources are used to transmit the base layer, more users will be left with no service at all, but more of the users capable of decoding the base layer will also be able to decode some of the enhancement layers. Thus, an optimal compromise for resource allocation needs to be found.

In the proposed framework, when 1 base layer and $K$ enhancement layers are to be used for the transmission of the broadcast video, the 16 Walsh codes are to be divided among the $K+1$ layers. We state that the system operates in mode

$$
\Upsilon_{x}=\left\{\left(C_{0}, R_{0}\right),\left(C_{1}, R_{1}\right), \ldots,\left(C_{K}, R_{K}\right)\right\}
$$

when $C_{0}$ code channels are allocated for the transmission of the base layer with a data-rate of $R_{0}$, and $C_{i}$ code channels are used for the transmission of the $i$ 'th enhancement layer with a data-rate of $R_{i}$ such that

$$
\sum_{i=0}^{K} C_{i}= \begin{cases}16 & \text { if } K=0 \\ 15 & \text { if } 0<K \leq 14\end{cases}
$$

Here, we assume that one code channel out of the 16 available is reserved as the control channel for any mode other than
TABLE II

Number of FEASIBLE MODES OF OPERATION VERSUS NuMBER OF LAYERS

\begin{tabular}{|c|c|}
\hline \hline Number of Layers & Number of Modes \\
\hline \hline 1 & 9 \\
\hline 2 & 203 \\
\hline 3 & 1219 \\
\hline 4 & 3313 \\
\hline 5 & 5249 \\
\hline 6 & 5676 \\
\hline \hline
\end{tabular}

The control channel is necessary to carry the information that describes which Walsh code channel is reserved for which layer. This information is transmitted continuously so that users joining in at any given time can begin decoding the broadcast video stream. There are a large number of possible modes, $\Upsilon_{x}, x=1,2, \ldots, X$ for the system operation but not all of these are feasible due to the constraint imposed by the effective coding rate as well as the receiver capabilities. Details on the limit imposed by the receiver is discussed in Section IV. Through a thorough count, one can easily determine the number of feasible modes of operation for the broadcast system for a given value of $K$. These are tabulated in Table II for $K \leq 6$.

The number of Walsh code channels reserved for each layer and the corresponding data-rates directly affect the average number of users that can successfully decode at least the base layer as well as the overall average throughput in the cell. The optimal compromise result for this problem aims to find the appropriate values for $C_{0}, R_{0}, \ldots, C_{K}, R_{K}$. Associated with each mode of operation, there exist a set of signal-to-noise (SNR) thresholds, $\gamma_{x, 0}, \ldots, \gamma_{x, K}$, that effectively divide the cell geography into $K+2$ regions as illustrated in Fig. 1 . When the system operates in mode $\Upsilon_{x}$, if a specific user, say user $u$ experiences an SNR value at time slot $t, \gamma(u, t)$, that is less than $\gamma_{x, 0}$ this user is unable to decode even the base layer. If, on the other hand, $\gamma(u, t)$ is between $\gamma_{x, 0}$ and $\gamma_{x, 1}$, the user can decode the base layer successfully but not any of the enhancement layers. In general, if $\gamma(u, t)$ is between $\gamma_{x, k}$ and $\gamma_{x, k+1}$, user $u$ can decode the base layer and the first $k$ enhancement layers. Let us assume that the broadcast system outage is defined as the percentage number of time slots where a user cannot successfully decode even the base layer video stream averaged across the user population. Assume that $M$ users, uniformly distributed within the cell, are capable of decoding different levels of data according to the data-rate matrix $\Omega_{\Upsilon_{x}}(u, t)$ where $\Upsilon_{x}$ is the system operation mode, $u$ is 
the user index and $t$ is the time slot index. The date-rate matrix is computed as follows:

$$
\Omega_{\Upsilon_{x}}(u, t)= \begin{cases}0, & \text { if } \gamma(u, t)<\gamma_{x, 0} \\ R_{0}, & \text { if } \gamma_{x, 0} \leq \gamma(u, t)<\gamma_{x, 1} \\ \vdots & \\ \sum_{i=0}^{K-1} R_{i}, & \text { if } \gamma_{x, K-1} \leq \gamma(u, t)<\gamma_{x, K} \\ \sum_{i=0}^{K} R_{i}, & \text { if } \gamma(u, t)>\gamma_{x, K}\end{cases}
$$

Then, the first objective is

$$
\min _{\Upsilon_{x}}\left(\sum_{u} \sum_{t} \delta_{\Omega_{\Upsilon_{x}}(u, t), 0}\right)
$$

where

$$
\delta_{i, j}= \begin{cases}1, & \text { if } i=j \\ 0, & \text { if } i \neq j\end{cases}
$$

Similarly, the average decodable video stream data-rate for the system can be calculated for a specific mode $\Upsilon_{x}$ as follows:

$$
\bar{R}_{\Upsilon_{x}}=\frac{1}{M T} \sum_{u=1}^{M} \sum_{t=1}^{T} \Omega_{\Upsilon_{x}}(u, t)
$$

where $M$ is the number of users, and $T$ is the duration of the video broadcast.

Thus, the second objective is:

$$
\max _{\Upsilon_{x}}\left(\bar{R}_{\Upsilon_{x}}\right)
$$

As stated before, the objectives of (5) and (8) are contradictory and thus cannot be simultaneously satisfied. We resort to the framework of multi-objective optimization to find the best compromise operating point in the Pareto-optimal sense for these two objectives in the next section.

\section{Multi-ObJective Optimization}

Multi-objective optimization aims to find the solution of an optimization problem with the set of multiple objectives $F=$ $\left\{f_{1}, f_{2}, \ldots, f_{P}\right\}$. A solution is called globally Pareto-optimal if any one of the objectives cannot be improved without degrading the other objectives for this solution [18].

Assume that the optimization problem under investigation consists of $P$ distinct, and possibly conflicting objective functions. Without any loss of generality, assume further that the problem in hand requires all of the objective functions to be minimized. Then, a Pareto-optimal solution, $s^{*}$ exists if there is no other feasible solution, $s$, that satisfies

$$
f_{p}(s) \leq f_{p}\left(s^{*}\right), \quad \forall p \in\{1,2, \ldots, P\}
$$

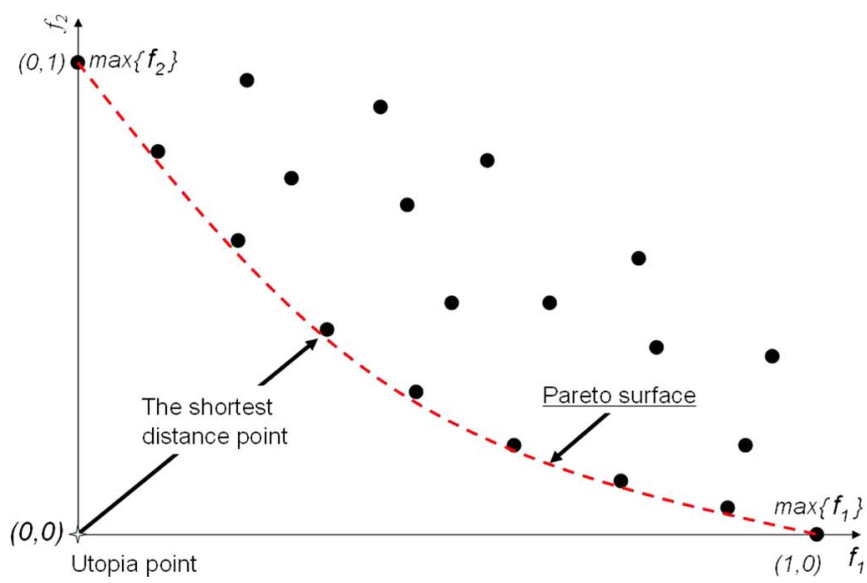

Fig. 3. The solution whose objective values are closest to the utopia point is chosen.

with at least one strict inequality. In other words, there is no other feasible solution that is at least as good as this Pareto-optimal solution in all of the objective functions and also is strictly better in one or more objective functions. In our formulation, $P=2$ and the objective functions are given by (5) and (8).

For single objective optimization problems, it is possible to have multiple optimal solutions resulting in a unique optimal functional value. It is also possible to have multiple Pareto-optimal solutions in multi-objective optimization problems. However, unlike the single objective problems, the multiple Paretooptimal solutions do not necessarily result in a unique functional value. In many instances, as different objective functions represent different system aspects on a specific scale, variance, and units of measurement, it is difficult to discriminate between these Pareto-optimal points and determine which one is better than the others. However, if relative importance weights for each of the objective functions is specified, a so-called best compromise solution may be determined.

In order to find the best compromise solution among the objective functions, $f_{p}$ 's, one has to first re-scale their range of values to lie in the intervals $\left[0, w_{p}\right]$, where $w_{p}$ is the importance weight of the $p$ 'th objective function:

$$
f_{p, \text { scaled }}(m)=w_{p} \frac{f_{p}(m)-f_{\min }(m)}{f_{\max }(m)-f_{\min }(m)}
$$

where $f_{\min }(n)$ and $f_{\max }(p)$ are the minimum and maximum values of the objective function, $f_{p}(m)$, respectively. Once scaling is done, all feasible operating points are mapped onto the $P$-dimensional space where each dimension represents one of the objectives. For $P=2$ and $w_{1}=w_{2}=1$, this is illustrated in Fig. 3.

In multi-objective optimization, an unfeasible operating point that optimizes all of the objective functions simultaneously is called the utopia point. When $P=2$, and both of the scaled objectives need to be minimized, this corresponds to the $(0,0)$ point in the two-dimensional objective space as illustrated in Fig. 3. 


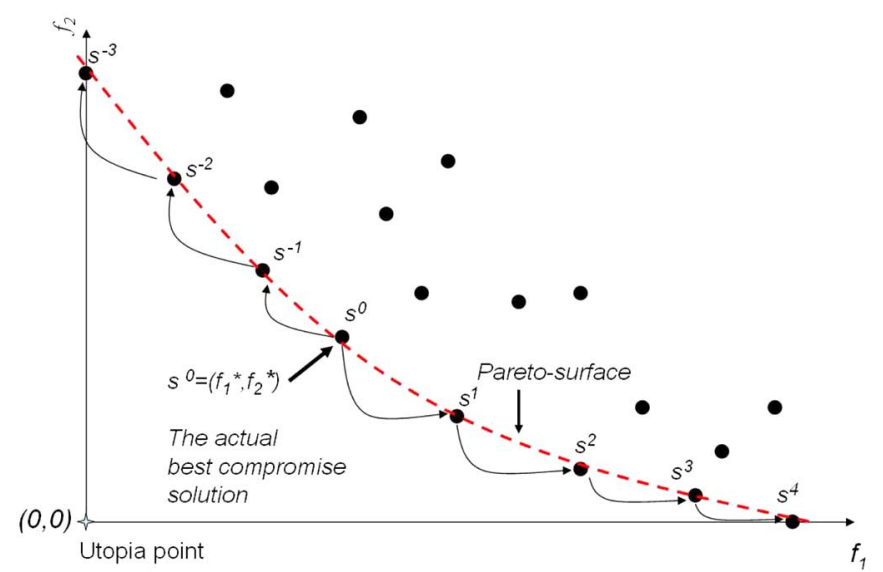

Fig. 4. Fine-tuning of the optimization decisions along the Pareto-optimal surface.

The best compromise solution is then found as the feasible point that is closest to the utopia point in the Euclidean-distance sense.

It may be necessary to impose constraints to the multi-objective optimization problem. In the proposed framework, for a given number of layers, the date-rates for the base and enhancement layers as well as the code space division are determined for the best compromise operating point. The two objectives of maximization of the base layer video coverage and maximization of the average decodable video data-rate may be achieved by selecting a very low data-rate for the base layer requiring a small portion of the code space, and allocating a remaining resources towards the transmission of high data-rate enhancement layers. However, this may result in an unacceptably poor basic video quality for users capable of decoding only the base layer. In practice, one may choose to put a lower bound on the base layer data-rate such that an acceptable basic video quality is available for all. When such a constraint is imposed on the multi-objective optimization, the best compromise solution becomes the point with the smallest Euclidean distance from the utopia point among operating points satisfying the constraint.

In the proposed broadcast video system, we set the importance weights of the two objective functions at $w_{1}=w_{2}=1$. To find the best compromise point for a given number of broadcast video layers with and without a constraint on the base layer data-rate, an exhaustive search is computationally feasible. This is because, the number of modes of operation is not large for the number of layers considered in the formulation as observed in Table II.

It is also possible to generate a solution that is better than the actual best compromise solution for one objective function, but worse for the others. This actually corresponds to fine-tuning the optimization decisions in favor of a selected optimization criterion along the multiple Pareto-optimal solutions creating the Patero-surface. For example, we can come up with a solution that provides better base layer video broadcast coverage with lower average throughput and vice versa. Knowing the client preferences, the server side may prefer to skip the original bestcompromise optimal solution and offer different solutions by utilizing this property as illustrated in Fig. 4.

\section{Simulation Results}

Extensive simulations have been conducted to assess the performance of the proposed broadcast video system. Details of the simulation platform are given in Section IV-A. Results are then presented in Section IV-B comparing non-SVC transmission to SVC transmission with different number of layers. Sensitivity of the system performance when the operating point deviates from the optimal one is discussed in Section IV-C.

\section{A. Simulation Platform}

The simulations are composed of three stages:

1) System Level Simulations

2) Physical Layer Simulations

3) SVC Video Coding Simulations

System level simulations model a 3-tier cellular layout with hexagonal cells having a maximum cell radius of $1000 \mathrm{~m}$. Here, the 3 tiers have 6,12 and 18 cells around the cell of interest, respectively. For the simulations a minimum distance between a base station and a mobile is set to be $35 \mathrm{~m}$. The base station transmission level is set to $40 \mathrm{dBm}$ and each base station in the system is assumed to use the same frequency $(2 \mathrm{GHz})$. It is assumed that this transmission level encompasses all other components of a link budget such as antenna gain, etc. The simulation only considers users in the center cell.

In the simulations, we drop 32 mobiles uniformly into the center cell. The simulations are divided into 60 second simulation time blocks. Each mobile is randomly repositioned every time block, simulating movement within a cell. The resulting position of the mobile is used in the path loss calculations of the signals from each of the base stations in the system. Fifty time blocks are used in the simulations resulting in 3000 seconds of broadcast simulation time. The same velocity is used for all the mobiles and is assumed constant for the entire simulation. The system is assumed to operate in an urban environment and path loss, shadow fading, multipath fading and mobility are taken into account using the ITU IMT-2000 channel models [19]. We consider two scenarios from [19], namely, the Pedestrian A and Vehicular B channels, where user velocities are $3 \mathrm{~km} / \mathrm{hr}$ and $100 \mathrm{~km} / \mathrm{hr}$, respectively. Many of the urban environmental factors such as building and base station heights, building separation distances are included in the calculations in these models.

In the simulations, we first calculate the path loss for each terminal and base station pair using the path loss models given in [19] for both of the channel models considered. This gives a set of path loss values for each user with respect to the center cell base station as well as to each of the outer cell base stations. A calculated mean received signal power from each base station based on the path loss model is used for the duration of the simulation time block.

Shadow fading cause small variations in the received signal power that vary slowly and is modeled with a Log-Normal distribution with zero mean and standard deviation of $4.3 \mathrm{~dB}$. The distribution has a correlation parameter that is a function of the mobile velocity as well as the geographical distance between the transmitter and the receiver [20]. In the simulations we assume that shadow fading is slow and thus can be modeled to be constant within $0.5 \mathrm{sec}$. intervals. 
TABLE III

PEDESTRIAN A AND Vehicular B TAPPED-DElay Line PARAMETERS

\begin{tabular}{|c|c|c|}
\hline \hline \multicolumn{3}{|c|}{ Pedestrian A } \\
\hline \hline Tap & Relative Delay (ns) & Average Power (dB) \\
\hline \hline 1 & 0 & 0 \\
\hline 2 & 110 & -9.7 \\
\hline 3 & 190 & -19.2 \\
\hline 4 & 410 & -22.8 \\
\hline \hline \multicolumn{3}{|c|}{ Vehicular B } \\
\hline \hline 1 & 0 & -2.5 \\
\hline 2 & 300 & 0 \\
\hline 3 & 8900 & -12.8 \\
\hline 4 & 12900 & -10 \\
\hline 5 & 17100 & -25.2 \\
\hline 6 & 20000 & -16 \\
\hline \hline
\end{tabular}

Multipath fading is modeled with a Rayleigh distribution having a Doppler power spectrum modeled using Clark's scattering model [19]. Unlike shadow fading, multipath fading is faster and is re-computed for each time slot $(=1.67 \mathrm{~ms})$. The effects of the wide-band channel is characterized using a tapped-delay line model for the channel impulse response. The ITU IMT-2000 channel models provide the number of taps, the time delay relative to the first tap and the average power relative to the strongest tap. These values are tabulated for the Pedestrian A and Vehicular B environments in Table III.

The system under consideration is for broadcast applications. Therefore, all of the base stations in the cellular layout will be transmitting the same signal at the same time. Then, unlike the traditional 3G systems, macro-diversity techniques may be employed to enhance the received signal-to-noise ratio of the mobile terminals. A macro-diversity system serves a mobile simultaneously using several base stations as illustrated in Fig. 5. The mobiles, then, will be able to capture the strongest resolvable paths from the closest base station as well as from the neighboring base stations and combine them using a RAKE receiver. In the simulations, it is assumed that the mobile has a RAKE receiver with ten fingers that lock on to the ten strongest resolvable paths. The receiver is assumed to be able to resolve between two paths that have a delay that is more than a chip time ( $\simeq 814 \mathrm{~ns})$. The paths that are not resolvable are assumed to contribute with a ratio based on the delay difference. The remaining resolvable paths contribute to the interference at the receiver. In the simulations, maximal ratio combining is assumed so that the received SNR is the sum of the SNR's of the ten fingers of the RAKE receiver.

The maximum SNR achievable in the mobile receiver is limited by several sources, including inter-chip interference induced by the base-band pulse shaping waveform, radio noise floor, A/D quantization error and adjacent carrier interference. In the system level simulations, the maximum achievable SNR value for the mobiles is assumed to be $13 \mathrm{~dB}$ [21]. Then, the effective SNR is given by

$$
\mathrm{SNR}_{\text {effective }}=\frac{1}{\frac{1}{\mathrm{SNR}_{\text {combined }}}+\frac{1}{10^{13} \mathrm{~dB} / 10}}
$$

where $\mathrm{SNR}_{\text {combined }}$ is the instantaneous SNR after maximalratio combining.

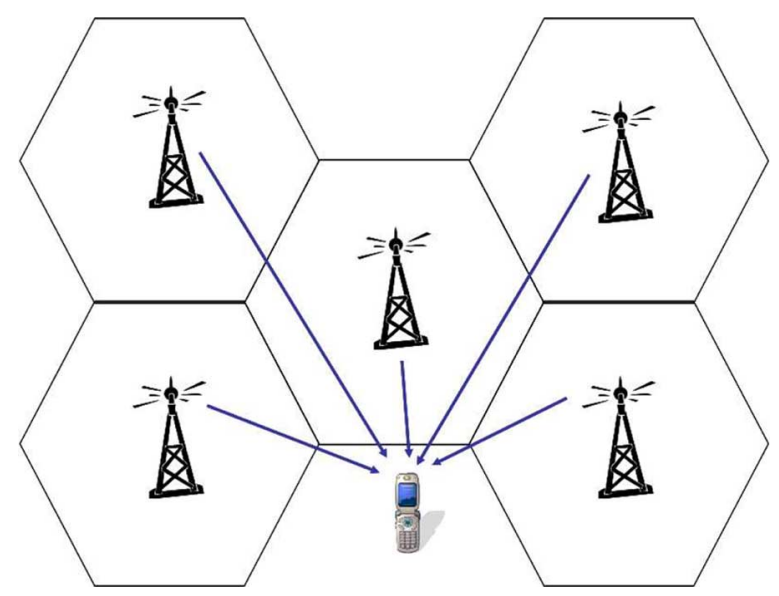

Fig. 5. Macro diversity with maximal ratio combining for the broadcast system.

In summary, system level simulations provide the effective SNR values for each of the 32 mobiles for each $1.67 \mathrm{~ms}$ long time-slot in the $3000 \mathrm{sec}$ of simulation time. Once system level simulations are complete, physical layer simulations are conducted to assess what data-rates each mobile can accommodate at each time slot.

For a given transmission scheme of the $1 \mathrm{xV}-\mathrm{DO}$ system corresponding to a specific transmission data-rate, the simulation of the physical layer is performed by processing 150000 randomly generated packets through the transmitter, AWGN (additive white Gaussian noise) channel and the receiver. All of the blocks illustrated in Fig. 2 are taken into account in the generation of the transmitter packets. The packets resulting from the receiver are then compared to the transmitted packets for the calculation of the packet error rate (PER). In the simulation, the channel noise power is swept in order to determine the SNR value that results in a $1 \%$ PER. The simulation is performed for each combination of data-rate and Walsh code division. The results are tabulated in Table IV. The "N/A" table entries correspond to modes of operation that are not feasible. The infeasibility stems from either the effective coding requirement discussed in the previous section or the fact that such a mode requires a SNR greater than $13 \mathrm{~dB}$ which is not achievable due to (11).

Once both the system level and physical layer simulations are complete, it is possible to find the base layer outage and average decodable video data-rate values for each broadcast system operating mode of (2) over the 32 users receiving the broadcast signal for a period of $3000 \mathrm{sec}$.

\section{B. Results}

We perform multi-objective optimization to find the best compromise operating points, $\Upsilon_{x}$, for the proposed 1xEV-DO based video broadcast system using different number of SVC layers. The optimization jointly considers the two objectives: (5) and (8), namely, maximization of the base layer video coverage and maximization of the average user decoded video data-rate. The limited system resources are divided among the base and enhancement layers optimally to find the best compromise. 
TABLE IV

Required C/I VAlues For the 1XEV-DO Data-Rates For 1\% PER as a Function of Number of Walsh Codes AVAILABLE

\begin{tabular}{|c|c|c|c|c|c|c|c|c|c|c|c|c|c|c|c|}
\hline & \multicolumn{15}{|c|}{ Number of Walsh Codes Available } \\
\hline Data-Rate & 16 & 14 & 13 & 12 & 11 & 10 & 9 & 8 & 7 & 6 & 5 & 4 & 3 & 2 & 1 \\
\hline 38.4 & -11.68 & -11.31 & -11.11 & \begin{tabular}{c|}
-10.83 \\
\end{tabular} & \begin{tabular}{c|}
-10.48 \\
\end{tabular} & $\begin{array}{l}-10.26 \\
\end{array}$ & 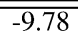 & $\begin{array}{c}-9.29 \\
\end{array}$ & 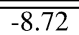 & $\begin{array}{l}-7.97 \\
\end{array}$ & $\begin{array}{c}-7.48 \\
\end{array}$ & "-6.11 & "-4.8 & $\overline{-13}$ & "-0.68 \\
\hline 76.8 & -9.3 & -8.73 & -8.51 & -8.01 & -7.64 & -7.48 & -6.72 & -6.2 & -5.82 & -4.72 & -3.68 & -2.96 & -2.38 & -0.63 & 3.79 \\
\hline 153.6 & -6.16 & -5.8 & -5.48 & -4.8 & -4.15 & -3.74 & -3.3 & -2.95 & -2.85 & -2.35 & -1.69 & -0.71 & 0.88 & 3.86 & N/A \\
\hline 307.2 & -3.91 & -2.82 & -2.31 & -1.88 & -1.51 & -1.25 & -1.1 & -0.87 & -0.16 & 0.66 & 1.79 & 3.59 & 7.18 & N/A & N/A \\
\hline 614.4 & -0.91 & -0.21 & 0.27 & 0.62 & 1.18 & 1.8 & 2.59 & 3.6 & 4.99 & 7.14 & N/A & N/A & N/A & N/A & N/A \\
\hline 921.6 & 1.65 & 2.7 & 3.19 & 3.65 & 4.29 & 5.1 & 6.2 & 7.79 & 10.65 & N/A & N/A & N/A & N/A & N/A & N/A \\
\hline 1228.8 & 3.79 & 4.69 & 5.28 & 5.88 & 6.63 & 7.56 & 8.95 & 11.25 & N/A & N/A & N/A & N/A & N/A & N/A & N/A \\
\hline 1843.2 & 7.8 & 10.5 & 12.63 & N/A & N/A & N/A & N/A & N/A & N/A & N/A & N/A & N/A & N/A & N/A & N/A \\
\hline 2457.6 & 11.3 & N/A & N/A & N/A & N/A & N/A & N/A & N/A & N/A & N/A & N/A & N/A & N/A & N/A & N/A \\
\hline
\end{tabular}

TABLE V

Best COMPRomise Operating Points AS A Function of Number of LAYERS

\begin{tabular}{|c|c|c|c|}
\hline \multicolumn{4}{|c|}{ Pedestrian A } \\
\hline Number of Layers & Unconstrained & $\mathrm{BL}_{\min } \geq 307.2 \mathrm{kbps}$ & $\mathrm{BL}_{\min } \geq 153.6 \mathrm{kbps}$ \\
\hline 1 & BL: 614.4 kbps with 16 Walsh codes & BL: 614.4 kbps with 16 Walsh codes & BL: 614.4 kbps with 16 Walsh codes \\
\hline 2 & $\begin{array}{l}\text { BL: } 614.4 \text { kbps with } 12 \text { Walsh codes } \\
\text { EL: } 153.6 \text { kbps with } 3 \text { Walsh codes }\end{array}$ & $\begin{array}{l}\text { BL: } 614.4 \text { kbps with } 12 \text { Walsh codes } \\
\text { EL: } 153.6 \text { kbps with } 3 \text { Walsh codes }\end{array}$ & $\begin{array}{l}\text { BL: } 614.4 \text { kbps with } 12 \text { Walsh codes } \\
\text { EL: } 153.6 \text { kbps with } 3 \text { Walsh codes }\end{array}$ \\
\hline 3 & $\begin{array}{l}\text { BL: } 307.2 \mathrm{kbps} \text { with } 6 \text { Walsh codes } \\
\text { EL: } 307.2 \mathrm{kbps} \text { with } 6 \text { Walsh codes } \\
\text { EL: } 153.6 \mathrm{kbps} \text { with } 3 \text { Walsh codes }\end{array}$ & $\begin{array}{l}\text { BL: } 307.2 \mathrm{kbps} \text { with } 6 \text { Walsh codes } \\
\text { EL: } 307.2 \mathrm{kbps} \text { with } 6 \text { Walsh codes } \\
\text { EL: } 153.6 \mathrm{kbps} \text { with } 3 \text { Walsh codes }\end{array}$ & $\begin{array}{l}\text { BL: } 307.2 \text { kbps with } 6 \text { Walsh codes } \\
\text { EL: } 307.2 \text { kbps with } 6 \text { Walsh codes } \\
\text { EL: } 153.6 \text { kbps with } 3 \text { Walsh codes }\end{array}$ \\
\hline 4 & $\begin{array}{l}\text { BL: } 38.4 \mathrm{kbps} \text { with } 1 \text { Walsh code } \\
\text { EL: } 38.4 \mathrm{kbps} \text { with } 1 \text { Walsh code } \\
\text { EL: } 38.4 \mathrm{kbps} \text { with } 1 \text { Walsh code } \\
\text { EL: } 614.4 \mathrm{kbps} \text { with } 12 \text { Walsh codes }\end{array}$ & $\begin{array}{l}\text { BL: } 307.2 \mathrm{kbps} \text { with } 6 \text { Walsh codes } \\
\text { EL: } 153.6 \mathrm{kbps} \text { with } 3 \text { Walsh codes } \\
\text { EL: } 153.6 \mathrm{kbps} \text { with } 3 \text { Walsh codes } \\
\text { EL: } 153.6 \mathrm{kbps} \text { with } 3 \text { Walsh codes }\end{array}$ & $\begin{array}{l}\text { BL: } 307.2 \mathrm{kbps} \text { with } 6 \text { Walsh codes } \\
\text { EL: } 153.6 \mathrm{kbps} \text { with } 3 \text { Walsh codes } \\
\text { EL: } 153.6 \mathrm{kbps} \text { with } 3 \text { Walsh codes } \\
\text { EL: } 153.6 \mathrm{kbps} \text { with } 3 \text { Walsh codes }\end{array}$ \\
\hline 5 & $\begin{array}{l}\text { BL: } 38.4 \mathrm{kbps} \text { with } 1 \text { Walsh code } \\
\text { EL: } 38.4 \mathrm{kbps} \text { with } 1 \text { Walsh code } \\
\text { EL: } 38.4 \mathrm{kbps} \text { with } 1 \text { Walsh code } \\
\text { EL: } 307.2 \mathrm{kbps} \text { with } 6 \text { Walsh codes } \\
\text { EL: } 307.2 \mathrm{kbps} \text { with } 6 \text { Walsh codes }\end{array}$ & $\begin{array}{l}\text { BL: } 307.2 \mathrm{kbps} \text { with } 6 \text { Walsh codes } \\
\text { EL: } 307.2 \mathrm{kbps} \text { with } 6 \text { Walsh codes } \\
\text { EL: } 76.8 \mathrm{kbps} \text { with } 1 \text { Walsh code } \\
\text { EL: } 76.8 \mathrm{kbps} \text { with } 1 \text { Walsh code } \\
\text { EL: } 76.8 \mathrm{kbps} \text { with } 1 \text { Walsh code }\end{array}$ & $\begin{array}{l}\text { BL: } 307.2 \mathrm{kbps} \text { with } 6 \text { Walsh codes } \\
\text { EL: } 307.2 \mathrm{kbps} \text { with } 6 \text { Walsh codes } \\
\text { EL: } 76.8 \mathrm{kbps} \text { with } 1 \text { Walsh code } \\
\text { EL: } 76.8 \mathrm{kbps} \text { with } 1 \text { Walsh code } \\
\text { EL: } 76.8 \mathrm{kbps} \text { with } 1 \text { Walsh code }\end{array}$ \\
\hline 6 & $\begin{array}{l}\text { BL: } 38.4 \mathrm{kbps} \text { with } 1 \text { Walsh code } \\
\text { EL: } 38.4 \mathrm{kbps} \text { with } 1 \text { Walsh code } \\
\text { EL: } 38.4 \mathrm{kbps} \text { with } 1 \text { Walsh code } \\
\text { EL: } 307.2 \mathrm{kbps} \text { with } 6 \text { Walsh codes } \\
\text { EL: } 153.6 \mathrm{kbps} \text { with } 3 \text { Walsh codes } \\
\text { EL: } 153.6 \mathrm{kbps} \text { with } 3 \text { Walsh codes }\end{array}$ & $\begin{array}{l}\text { BL: } 307.2 \mathrm{kbps} \text { with } 6 \text { Walsh codes } \\
\text { EL: } 153.6 \mathrm{kbps} \text { with } 3 \text { Walsh codes } \\
\text { EL: } 153.6 \mathrm{kbps} \text { with } 3 \text { Walsh codes } \\
\text { EL: } 76.8 \mathrm{kbps} \text { with } 1 \text { Walsh code } \\
\text { EL: } 76.8 \mathrm{kbps} \text { with } 1 \text { Walsh code } \\
\text { EL: } 76.8 \mathrm{kbps} \text { with } 1 \text { Walsh code }\end{array}$ & $\begin{array}{l}\text { BL: } 307.2 \mathrm{kbps} \text { with } 6 \text { Walsh codes } \\
\text { EL: } 153.6 \mathrm{kbps} \text { with } 3 \text { Walsh codes } \\
\text { EL: } 153.6 \mathrm{kbps} \text { with } 3 \text { Walsh codes } \\
\text { EL: } 76.8 \mathrm{kbps} \text { with } 1 \text { Walsh code } \\
\text { EL: } 76.8 \mathrm{kbps} \text { with } 1 \text { Walsh code } \\
\text { EL: } 76.8 \mathrm{kbps} \text { with } 1 \text { Walsh code }\end{array}$ \\
\hline \multicolumn{4}{|c|}{ Vehicular B } \\
\hline Number of Layers & Unconstrained & $\mathrm{BL}_{\min } \geq 153.6 \mathrm{kbps}$ & $\mathrm{BL}_{\min } \geq 76.8 \mathrm{kbps}$ \\
\hline 1 & BL: 614.4 kbps with 16 Walsh codes & BL: 614.4 kbps with 16 Walsh codes & BL: 614.4 kbps with 16 Walsh codes \\
\hline 2 & $\begin{array}{l}\text { BL: } 307.2 \text { kbps with } 8 \text { Walsh codes } \\
\text { EL: } 307.2 \text { kbps with } 7 \text { Walsh codes }\end{array}$ & $\begin{array}{l}\text { BL: } 307.2 \text { kbps with } 8 \text { Walsh codes } \\
\text { EL: } 307.2 \text { kbps with } 7 \text { Walsh codes }\end{array}$ & $\begin{array}{l}\text { BL: } 307.2 \text { kbps with } 8 \text { Walsh codes } \\
\text { EL: } 307.2 \text { kbps with } 7 \text { Walsh codes }\end{array}$ \\
\hline 3 & $\begin{array}{l}\text { BL: } 38.4 \text { kbps with } 1 \text { Walsh code } \\
\text { EL: } 307.2 \mathrm{kbps} \text { with } 7 \text { Walsh codes } \\
\text { EL: } 307.2 \mathrm{kbps} \text { with } 7 \text { Walsh codes }\end{array}$ & $\begin{array}{l}\text { BL: } 153.6 \mathrm{kbps} \text { with } 4 \text { Walsh codes } \\
\text { EL: } 153.6 \mathrm{kbps} \text { with } 4 \text { Walsh codes } \\
\text { EL: } 307.2 \mathrm{kbps} \text { with } 7 \text { Walsh codes }\end{array}$ & $\begin{array}{l}\text { BL: } 153.6 \mathrm{kbps} \text { with } 4 \text { Walsh codes } \\
\text { EL: } 153.6 \mathrm{kbps} \text { with } 4 \text { Walsh codes } \\
\text { EL: } 307.2 \mathrm{kbps} \text { with } 7 \text { Walsh codes }\end{array}$ \\
\hline 4 & $\begin{array}{l}\text { BL: } 307.2 \mathrm{kbps} \text { with } 8 \text { Walsh codes } \\
\text { EL: } 153.6 \mathrm{kbps} \text { with } 4 \text { Walsh codes } \\
\text { EL: } 38.4 \mathrm{kbps} \text { with } 1 \text { Walsh code } \\
\text { EL: } 76.8 \mathrm{kbps} \text { with } 2 \text { Walsh codes }\end{array}$ & $\begin{array}{l}\text { BL: } 307.2 \mathrm{kbps} \text { with } 8 \text { Walsh codes } \\
\text { EL: } 153.6 \mathrm{kbps} \text { with } 4 \text { Walsh codes } \\
\text { EL: } 38.4 \mathrm{kbps} \text { with } 1 \text { Walsh code } \\
\text { EL: } 76.8 \mathrm{kbps} \text { with } 2 \text { Walsh codes }\end{array}$ & $\begin{array}{l}\text { BL: } 307.2 \mathrm{kbps} \text { with } 8 \text { Walsh codes } \\
\text { EL: } 153.6 \mathrm{kbps} \text { with } 4 \text { Walsh codes } \\
\text { EL: } 38.4 \mathrm{kbps} \text { with } 1 \text { Walsh code } \\
\text { EL: } 76.8 \mathrm{kbps} \text { with } 2 \text { Walsh codes }\end{array}$ \\
\hline 5 & $\begin{array}{l}\text { BL: } 307.2 \text { kbps with } 8 \text { Walsh codes } \\
\text { EL: } 153.6 \mathrm{kbps} \text { with } 4 \text { Walsh codes } \\
\text { EL: } 38.4 \mathrm{kbps} \text { with } 1 \text { Walsh code } \\
\text { EL: } 38.4 \mathrm{kbps} \text { with } 1 \text { Walsh code } \\
\text { EL: } 38.4 \mathrm{kbps} \text { with } 1 \text { Walsh code }\end{array}$ & $\begin{array}{l}\text { BL: } 307.2 \mathrm{kbps} \text { with } 8 \text { Walsh codes } \\
\text { EL: } 153.6 \mathrm{kbps} \text { with } 4 \text { Walsh codes } \\
\text { EL: } 38.4 \mathrm{kbps} \text { with } 1 \text { Walsh code } \\
\text { EL: } 38.4 \mathrm{kbps} \text { with } 1 \text { Walsh code } \\
\text { EL: } 38.4 \mathrm{kbps} \text { with } 1 \text { Walsh code }\end{array}$ & $\begin{array}{l}\text { BL: } 307.2 \text { kbps with } 8 \text { Walsh codes } \\
\text { EL: } 153.6 \text { kbps with } 4 \text { Walsh codes } \\
\text { EL: } 38.4 \text { kbps with } 1 \text { Walsh code } \\
\text { EL: } 38.4 \text { kbps with } 1 \text { Walsh code } \\
\text { EL: } 38.4 \text { kbps with } 1 \text { Walsh code }\end{array}$ \\
\hline 6 & $\begin{array}{l}\text { BL: } 307.2 \mathrm{kbps} \text { with } 8 \text { Walsh codes } \\
\text { EL: } 38.4 \mathrm{kbps} \text { with } 1 \text { Walsh code } \\
\text { EL: } 38.4 \mathrm{kbps} \text { with } 1 \text { Walsh code } \\
\text { EL: } 38.4 \mathrm{kbps} \text { with } 1 \text { Walsh code } \\
\text { EL: } 76.8 \mathrm{kbps} \text { with } 2 \text { Walsh codes } \\
\text { EL: } 76.8 \mathrm{kbps} \text { with } 2 \text { Walsh codes }\end{array}$ & $\begin{array}{l}\text { BL: } 307.2 \mathrm{kbps} \text { with } 8 \text { Walsh codes } \\
\text { EL: } 38.4 \mathrm{kbps} \text { with } 1 \text { Walsh code } \\
\text { EL: } 38.4 \mathrm{kbps} \text { with } 1 \text { Walsh code } \\
\text { EL: } 38.4 \mathrm{kbps} \text { with } 1 \text { Walsh code } \\
\text { EL: } 76.8 \mathrm{kbps} \text { with } 2 \text { Walsh codes } \\
\text { EL: } 76.8 \mathrm{kbps} \text { with } 2 \text { Walsh codes }\end{array}$ & $\begin{array}{l}\text { BL: } 307.2 \text { kbps with } 8 \text { Walsh codes } \\
\text { EL: } 38.4 \text { kbps with } 1 \text { Walsh code } \\
\text { EL: } 38.4 \text { kbps with } 1 \text { Walsh code } \\
\text { EL: } 38.4 \text { kbps with } 1 \text { Walsh code } \\
\text { EL: } 76.8 \text { kbps with } 2 \text { Walsh codes } \\
\text { EL: } 76.8 \text { kbps with } 2 \text { Walsh codes }\end{array}$ \\
\hline
\end{tabular}

An unconstrained optimization naturally results in the best compromise operating point. However, it may yield operating points that are not practical, in that, the base layer data-rates may be unacceptably low for these points. To ensure a respectable basic quality for all users, it may be necessary to place a constraint on the minimum base layer data-rate. Depending on the aimed application, terminal resolution and the specific SVC coding algorithm in use, this rate may be determined. We investigate scenarios where the minimum base layer rates are chosen to be $307 \mathrm{kbps}$ and $153.6 \mathrm{kbps}$ for 


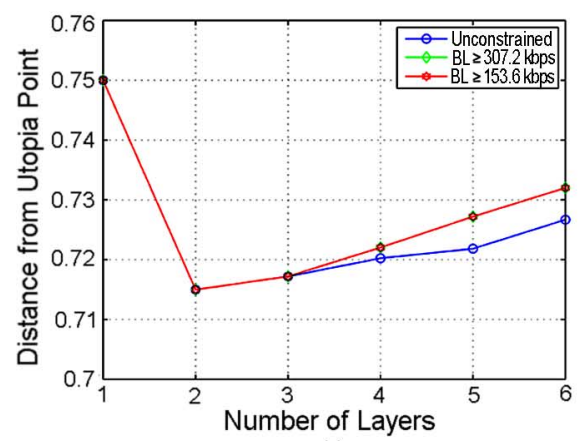

(a)

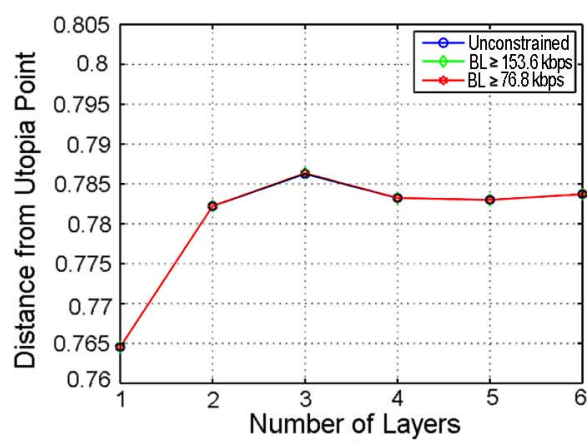

(b)

Fig. 6. Distance from the utopia point versus number of layers for (a) Pedestrian A \& (b) Vehicular B channels.

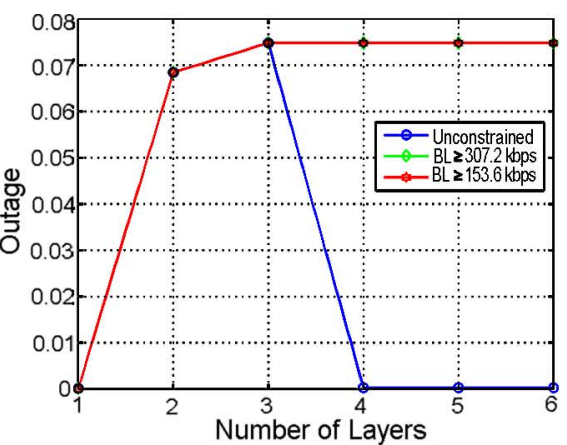

(a)

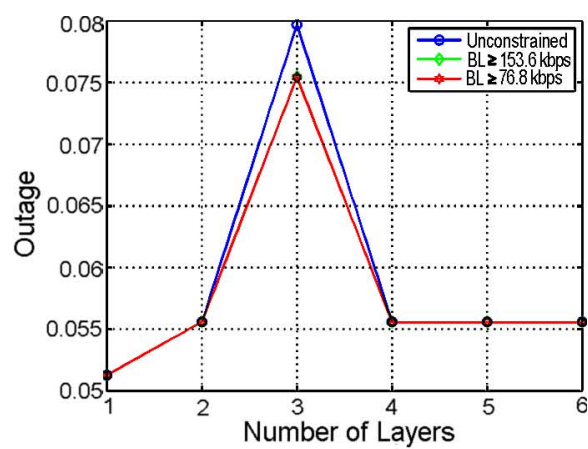

(b)

Fig. 7. Outage versus number of layers for unconstrained and constrained optimization for (a) Pedestrian A \& (b) Vehicular B channels.

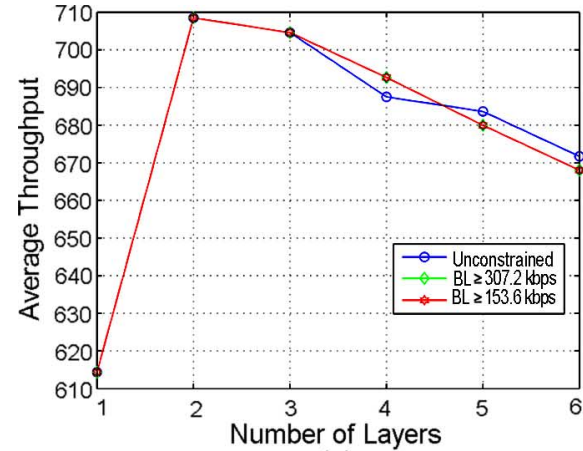

(a)

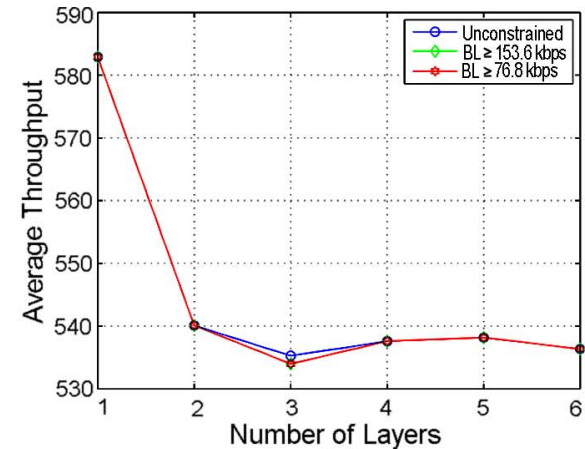

(b)

Fig. 8. Average throughput versus number of layers for unconstrained and constrained optimization for (a) Pedestrian A \& (b) Vehicular B channels.

the Pedestrian A channel, and $153.6 \mathrm{kbps}$ and $76.8 \mathrm{kbps}$ for the Vehicular B channel. We choose lower data-rates for the vehicular channel since it is much more difficult to maintain high rates in wireless systems with high mobility.

The resulting optimal operating points are tabulated in Table $\mathrm{V}$ for both channels for unconstrained and base layer data-rate constrained optimization scenarios. The distances of these operating points from the utopia point and the corresponding base layer video outage and system throughput values are plotted in Figs. 6-8, respectively.

We have stated that the decoded video data-rate and the video quality, measured by PSNR, are related. This relationship depends on the type of video source coding used, as well as the error correction and concealment techniques employed. To assess the results of the multi-objective optimization framework in a practical setting, we conduct PSNR-scalable SVC video coding simulations for the best compromise solutions given in Table $\mathrm{V}$ to find the corresponding PSNR values for the broadcast streams. We use the standard "Harbour" reference sequence at the CIF resolution of $352 \times 288$. This sequence is looped in the simulation so that 150000 physical layer packets constitute the broadcast stream. The SVC software available as the JSVM code at the CVS repository of JVT [23] is used for encoding this sequence with quantization parameters adjusted to yield source data-rates as close to the physical layer transmission data-rates as possible. The intra period is set to 64 pictures and a GOP size of 16 pictures is chosen. The video frame-rate is chosen to be $15 \mathrm{~Hz}$ for the operating points providing a base layer transmission data-rate of $614.4 \mathrm{kbps}$ and $7.5 \mathrm{~Hz}$ for the operating points providing a base layer transmission data-rate of $307.2 \mathrm{kbps}$. 
TABLE VI

PSNR LEVELS AND EFFECTIVE VIDEO DATA-RATES FOR BEST COMPROMISE OPERATING POINTS

\begin{tabular}{|c|c|c|c|c|c|}
\hline \multicolumn{6}{|c|}{ Pedestrian A } \\
\hline Number of Layers & Tx Data-Rate (kbps) & Max PSNR (dB) & Min PSNR (dB) & Video Data-Rate (kbps) & $\%$ of Users Decoding \\
\hline 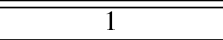 & 614.4 & 30.2895 & 27.5481 & 276.60 & $99.994 \%$ \\
\hline 2 & BL only: 614.4 & 30.2895 & 27.5481 & 276.60 & $93.155 \%$ \\
\hline & BL+EL: 768.0 & 31.1893 & 28.0926 & 429.77 & $88.638 \%$ \\
\hline \multicolumn{6}{|c|}{ Vehicular B } \\
\hline Number of Layers & Tx Data-Rate (kbps) & Max PSNR (dB) & Min PSNR (dB) & Video Data-Rate (kbps) & $\%$ of Users Decoding \\
\hline 1 & 614.4 & 30.2895 & 27.5481 & 276.60 & $94.871 \%$ \\
\hline \multirow[t]{2}{*}{2} & $\begin{array}{l}\text { BL only: } 307.2 \\
\text { BL+EL: } 614.4\end{array}$ & $\begin{array}{l}28.9763 \\
31.6747\end{array}$ & $\begin{array}{l}25.2487 \\
26.1658\end{array}$ & $\begin{array}{l}147.67 \\
381.09\end{array}$ & $\begin{array}{l}94.441 \% \\
81.366 \%\end{array}$ \\
\hline & BL+EL: 614.4 & $31.6 / 4 /$ & 26.1658 & 381.09 & $81.366 \%$ \\
\hline
\end{tabular}

The video source coder generates video frames whose sizes are not constant and may vary significantly over the course of the video stream. While one frame may fill only a small portion of the physical layer transmission packet, another may occupy multiple packets. In the simulations we assume that video frames are not divided between multiple physical layer packets unless necessary. Therefore some frame fill inefficiencies are unavoidable.

Two types of video frames exist: discardable and non-discardable. The source coder generates base layer frames as nondiscardable and the enhancement layer frames as discardable. The loss of even a single non-discardable frame hurts the video quality, and thus the PSNR value, significantly. Recall that the physical layer of the wireless system operates at $1 \%$ packet error rate. Therefore additional protection of the non-discardable frames is necessary to ensure acceptable video quality at the receiver. We employ a simple, rate $1 / 2$ block code to protect the non-discardable frames. No additional protection is provided for the non-discardable frames. The SVC considered uses a "frame copy" error concealment algorithm [24] where each pixel of the concealed frame is copied from the corresponding pixel of the previous decoded reference frame. Our simulations show that error concealment is very rarely needed when the non-discardable frames are protected by the rate $1 / 2$ block code.

The average PSNR values are calculated in two ways:

1) When the received video stream (of $15 \mathrm{~Hz}$ frame rate) is compared to the down-sampled version of the original Harbour sequence of $30 \mathrm{~Hz}$ frame rate

2) When the up-sampled received video stream is compared to the original Harbor sequence of $30 \mathrm{~Hz}$ frame rate

These PSNR values correspond to the maximum and minimum achievable levels, respectively. The maximum and minimum PSNR values, as well as the effective video source data-rates transmitted are tabulated in Table VI for the best compromise operating points when 1 and 2 layers are employed. When there are 2 layers ( 1 base layer and 1 enhancement layer), some users will be able to decode both layers, some will only be able to decode the base layer and the remaining will be able to decode neither. The percentage of users in these categories, their corresponding maximum and minimum PSNR levels as well as their effective video data-rates are given in this table as well. The results confirm the direct relationship between the transmission data-rate and the video quality observed at the receiver.

From the multi-objective optimization results, we observe that a single layer transmission (which effectively requires a non-SVC video coding algorithm) enables the system to transmit at the $614.4 \mathrm{kbps}$ data-rate for both Pedestrian A and Vehicular B channels. The outages observed are $0.006 \%$ and $5.129 \%$ for these channels, respectively, resulting in average decoded data-rates of $614.36 \mathrm{kbps}$ and $582.89 \mathrm{kbps}$. In other words, when the system broadcasts video using non-scalable coding, the stationary users are almost always capable of successfully decoding the video packets whereas users traveling at $100 \mathrm{~km} / \mathrm{hr}$ are able to decode them $94.8 \%$ of the time. The $614.4 \mathrm{kbps}$ data-rate is used to transmit a video data-rate of $305.77 \mathrm{kbps}$ since a rate $1 / 2$ block code is used to protect the non-discardable video frames. The corresponding maximum and minimum PSNR levels of the decoded broadcast stream are $30.2895 \mathrm{~dB}$ and $27.5481 \mathrm{~dB}$, respectively.

We observe from Fig. 6 that the optimal compromise point is reached with two layers for the Pedestrian A channel and with only a single layer for the Vehicular B channel. When we further investigate Figs. 7 and 8 as well as Table VI, we observe for the Pedestrian A channel that while the second layer buys the system $94.13 \mathrm{kbps}$ in the average transmission data-rate, and correspondingly a PSNR increase of approximately $0.9 \mathrm{~dB}$ for $88.64 \%$ of the user population that is capable of decoding both the base and the enhancement layers, this costs an outage increase from $0.006 \%$ to $6.845 \%$. In the following section we investigate whether it is possible to increase the data-rate and the PSNR over the single layer transmission while maintaining a reasonable outage level for the Pedestrian A channel. For the Vehicular B channel, on the other hand, we observe that the inclusion of a second layer results in a performance degradation for both objectives. Additionally, the broadcast video stream frame-rate needs to be reduced to $7.5 \mathrm{~Hz}$ with the inclusion of the second layer since the $307.2 \mathrm{kbps}$ transmission-rate for the base layer cannot support the $15 \mathrm{~Hz}$ CIF video. As observed in Table VI, this results in an additional degradation in the observed PSNR levels relative to the non-layered transmission.

For both types of channels, as the number of layers are increased, the overall performance of the system is reduced since the distance between the best compromise and the utopia points increases. When constraints are placed on the minimum base layer transmission data-rate, the deviation from the overall best compromise point becomes more pronounced with increasing number of layers. This is expected because the system resources, code space in our case, are limited. When we attempt to divide this limited resource between more and more parallel channels, after a point, the resources allocated for each of the 
layers become too thin to sustain the system performance over the harsh wireless channel.

Even though the single layer optimal compromise points for both Pedestrian A and Vehicular B channels are the same, we observe that while a second layer increases the system performance in terms of the distance from the utopia point for the Pedestrian A channel, it does the opposite for the Vehicular B channel. The reason for this difference lies in the average $C / I$ values observed by the users in these channels. The 1xEV-DO system provides rate adaptation in the wireless environment through adaptive modulation and coding. However, this adaptation is possible only in discrete steps since only 12 modes with 8 distinct data-rates are defined in $1 \mathrm{xEV}-\mathrm{DO}$. Then, the system is not always able to distinguish between users that have distinctly different received $C / I$ values. For example, as can be seen from Table IV, users with $C / I$ values of $-0.91 \mathrm{~dB}$ and $1.649 \mathrm{~dB}$ are both able to decode a single layer video stream of $614.4 \mathrm{kbps}$ but not the next data-rate offered, which is $921.6 \mathrm{kbps}$. From a resource allocation point of view, the introduction of multiple layers in the transmission allows for finer division of the $C / I$ scale. If, for example, most of the users have $C / I$ values greater than $-0.21 \mathrm{~dB}$, from Table IV, we observe that we can provide this population the $614.4 \mathrm{kbps}$ video stream using 14 codes, leaving 1 code for transmission of a second layer and still not observe a significant increase in the outage. If the $C / I$ value for most of the users in this population is greater than $0.62 \mathrm{~dB}$, then it is possible to provide the video service at $614.4 \mathrm{kbps}$ using only 12 codes, leaving 3 codes for a second layer. Then, further optimization yields us how best to use these additional codes to increase the average user decoded data-rate. While both the Pedestrian A and Vehicular B channels allow for a $614.4 \mathrm{kbps}$ transmission using a non-SVC algorithm, albeit at significantly different outage values, this data-rate is supported at drastically different average $C / I$ values of the user population. While the average $C / I$ is close to $-0.21 \mathrm{~dB}$ for the Vehicular $\mathrm{B}$ channel, it is greater than $0.62 \mathrm{~dB}$ for the Pedestrian A channel. It is this difference and the 16-step division of the code space in 1xEV-DO that results in the optimal layers of 2 and 1, for the Pedestrian A and Vehicular B channels, respectively.

\section{Sensitivity Analysis}

The optimal compromise operating point is reached with two layers for the Pedestrian A channel. However, we observe that this comes at the expense of a significant outage of $6.845 \%$. This may be deemed unacceptably high. Focusing our attention on the scenario where the base-layer minimum transmission data-rate is set at $307.2 \mathrm{kbps}$, we perform a sensitivity analysis. To assess the sensitivity of the objectives of (5) and (8) to departures from the optimum operating point we first rank all operating points with increasing distances from the utopia point. We conduct the sensitivity analysis for the base-layer video outage, and thus we investigate the operating points that are nearest ranked to the optimal point and that have smaller outage values. Obviously if one of these points were to be employed instead of the optimum point, the overall system performance in terms of the distance from the utopia point would be worse. The results,
TABLE VII

SENSITIVITY ANALYSIS FOR 2 LAYER TRANSMISSION WITH $\mathrm{BL}_{\text {min }} \geq 307 \mathrm{kbps}$ FOR THE PEDESTRIAN A CHANNEL

\begin{tabular}{|c|c|c|c|}
\hline \hline & Optimal Compromise & Second Best & Third Best \\
\hline \hline BL & $614.4 \mathrm{kbps}$ & $614.4 \mathrm{kbps}$ & $614.4 \mathrm{kbps}$ \\
\hline EL & $153.6 \mathrm{kbps}$ & $307.2 \mathrm{kbps}$ & $76.8 \mathrm{kbps}$ \\
\hline Outage & $6.845 \%$ & $6.845 \%$ & $0.329 \%$ \\
\hline Throughput & $708.49 \mathrm{kbps}$ & $658.87 \mathrm{kbps}$ & $649.542 \mathrm{kbps}$ \\
\hline Max PSNR & $31.1893 \mathrm{~dB}$ & $31.9734 \mathrm{~dB}$ & $30.7169 \mathrm{~dB}$ \\
\hline Min PSNR & $28.0926 \mathrm{~dB}$ & $28.5733 \mathrm{~dB}$ & $27.8003 \mathrm{~dB}$ \\
\hline \hline
\end{tabular}

tabulated in Table VII, are for two of these points for the Pedestrian A channel operating with two layers. It is observed that if the provider is more interested in reducing the base-layer video outage rather than providing a high average video data-rate and thus high video quality, it may choose one of these points as the operating point. When the third best operating point is chosen for example, the outage is reduced to $0.329 \%$ at the expense of an average transmission data-rate drop of $58.95 \mathrm{kbps}$ corresponding to a PSNR drop of $0.2923 \mathrm{~dB}$ between the minimum values and $0.4724 \mathrm{~dB}$ between the maximum values. However, even with this drop, the third best operating point for this scenario still yields a slight advantage over the single layer operating point which provides an average data-rate of $614.36 \mathrm{kbps}$ with maximum and minimum PSNR values of $30.2895 \mathrm{~dB}$ and $27.5481 \mathrm{~dB}$, respectively, and an outage of $0.006 \%$.

In a practical scenario, users traveling at different velocities will be present in the system. While a very modest increase in the system performance is possible with a second layer for stationary users, we observe that the loss this additional layer brings is very pronounced for the high mobility users.

\section{CONCLUSIONS}

In this paper, building on the $1 \mathrm{xEV}-\mathrm{DO}$ system, we propose a novel multi-objective optimization framework for determining the best compromise division of the code space for wireless video broadcasting. The main aim of the proposed algorithm is to provide the best compromise between maximizing the average decoded video data-rate and maximizing the geographical coverage area for a basic broadcast video quality. The work differentiates itself from the rest on two fronts. First, here we propose a wireless video broadcasting scheme where the division of resources is due to the optimal compromise among the two goals of the system. Second, in this paper we propose to divide the system resources in the code domain. This way, it is possible to use the same modulation and channel coding schemes to all layers, simplifying the overall hardware design and decoding and demodulation complexity.

The wireless broadcast system benefits from macro diversity across the serving base stations and achieves data-rates in the order of $614.4 \mathrm{kbps}$ over the $1.25 \mathrm{MHz}$ channel. While this rate is achieved with almost zero outage for stationary users, high mobility users experience modest outages. The use of scalable video coding is not desirable for this scenario as the use of a second layer provides a very modest benefit for stationary users but causes a significant performance drop for users with high mobility. 


\section{REFERENCES}

[1] G. Faria, J. A. Henriksson, E. Stare, and P. Talmola, "DVB-H: Digital broadcast services to handheld devices," Proceedings of the IEEE, vol. 94, pp. 194-209, January 2006.

[2] Qualcomm, "Media-Flo: Flo Technology Brief," May 6, 2005 [Online]. Available: http://www.qualcomm.com/mediaflo/news/pdf/ flo_whitepaper.pdf

[3] TIA/EIA/IS-856, "cdma2000 High Rate Packet Data Air Interface Specification" 3GPP2, C.S0024, v4.0, October 2002.

[4] H. Kwon, Y. Kim, J. K. Han, D. Kim, H. W. Lee, and Y. K. Kim, "Performance Evaluation of High-Speed Packet Enhancement on cdma2000 1xEV-DV," IEEE Communications Magazine, vol. 43, pp. 67-73, April 2005.

[5] R. Love, A. Ghosh, X. Weimin, and R. Ratasuk, "Performance of 3GPP high speed downlink packet access (HSDPA)," in Proceedings of the IEEE VTC-Fall, Los Angeles, CA, USA, September 26-29, 2004.

[6] J. R. Ohm, "Advances in scalable video coding," Proceedings of the IEEE, vol. 93, pp. 42-56, January 2005.

[7] K. Shen and E. J. Delp, "Wavelet based rate scalable video compression," IEEE Trans. in Circuits and Systems for Video Technology, vol. 9, pp. 109-122, February 1999.

[8] U. Horn, G. Girod, and B. Belzer, "Scalable video coding for multimedia applications and robust transmission over wireless channels," in International Workshop on Packet Video, Brisbane, Australia, March 17-18, 1996.

[9] M. Khansari, A. Jalali, E. Dobios, and P. Mermelstein, "Low bit-rate video transmission over fading channels for wireless microcellular systems," IEEE Trans. on Circuits and Systems for Video Technology, vol. 6, pp. 1-11, February 1996

[10] D. Wu, Y. T. Hou, and Y. Q. Zhang, "Scalable video coding and transport over broad-band wireless networks," Proceedings of the IEEE, vol. 89, no. 1, pp. 6-20, January 2001.

[11] M. Van der Schaar and J. Meehan, "Robust transmission of MPEG-IV scalable video over 4G wireless networks," in Proceedings of the IEEE ICIP, Rochester, NY, USA, June 24-28, 2002.

[12] Z. Cakareski, N. Ahmed, A. Dhar, and B. Aazhang, "Multilevel coding of broadcast video over wireless channels," in Proceedings of the IEEE ICASSP, Orlando, FL, USA, May 13-17, 2002.

[13] T. Schierl, H. Schwarz, D. Marpe, and T. Wiegand, "Wireless broadcasting using the scalable extension of H.264/AVC," in Proceedings of the ICME, Amsterdam, The Netherlands, July 6-8, 2005.

[14] N. Jiang, "Wireless Broadcast Service," M.Sc. Thesis, Rutgers University, , October 2002

[15] S. Kwon, K. R. Rao, O. Kwon, and T. Kim, "Joint bandwidth allocation for user-required picture quality ratio among multiple video sources," IEEE Trans. on Broadcasting, vol. 51, pp. 287-295, September 2005.

[16] H. Schwarz, D. Marpe, T. Schierl, and T. Wiegand, "Combined scalability support for the scalable extension of H.264/AVC," in Proceedings of ICME, Amsterdam, The Netherlands, July 6-8, 2005.

[17] A. J. Viterbi, "Very low rate convolution codes for maximum theoretical performance of spread-spectrum multiple-access channels," IEEE Journal on Selected Areas in Communications, vol. 8, pp. 641-649, May 1990.

[18] Y. Lim, P. Floquet, and X. Joulia, "Multiobjective optimization considering economics and environmental impact," in Proceedings of the ECCE2, October 5-7, 1999.
[19] ITU-R, "Guidelines for Evaluation of Radio Transmission Technologies for IMT-2000," Recommendation ITU-R M.1225, 1997.

[20] M. Gudmundson, "Correlation model for shadow fading in mobile radio systems," Electronics Letters, vol. 27, no. 23, pp. 2145-2146, November 1991.

[21] Nokia, "1xEV-DO Evaluation Methodology," 3GPP2 Technical Specification C30-DOAH-20030505-004, May 5, 2003.

[22] "Harbour Test Sequence," [Online]. Available: ftp.tnt.uni-hannover.de/ pub/svc/testsequences/

[23] Nokia and VisioWave, JVT-O007, AHG Report: JSVM \& WD Test, SVC Software JVT of ISO/IEC MPEG \& ITU-T VCEG Document, April 16-22, 2005

[24] T. Stockhammer, T. Wiegand, T. Oelbaum, and F. Obermeier, "Video coding and transport layer techniques for H.264/AVC-based transmission over packet-lossy networks," in Proceedings of the IEEE ICIP, Barcelona, Spain, September 14-17, 2003.

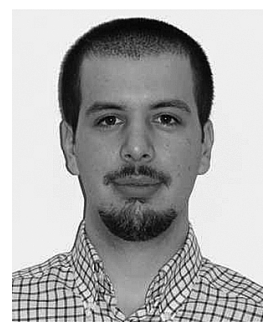

Çağdas Atıcı is currently a Ph.D. candidate at the Wireless Communications Laboratory, Koç University, İstanbul, Turkey and is a recipient of the Tübitak Ph.D. Fellowship. He received his B.Sc. degree in Electrical and Electronics Engineering, also from Koç University in 2005 where he had the second highest GPA in his graduating class. He received the Dean's Award in 2005 due to his significant contribution to Koç University at large while maintaining a high scholarly achievement. His current research interests include wireless multimedia broadcasting, scalable video coding, CDMA, OFDM and fountain coding.

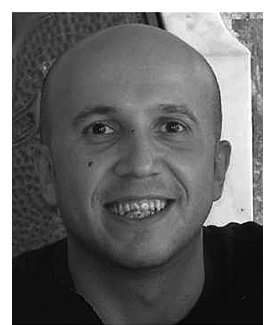

M. Oğuz Sunay has been a faculty at the Department of Electrical and Electronics Engineering of Koc University, İstanbul, Turkey since January 2001. From 1996 to 1998 he was a Research Engineer at Nokia Research Center, Irving, Texas, USA and from 1998 to 2001 he was a Member of Technical Staff at Bell Laboratories, Lucent Technologies, Whippany, New Jersey, USA. He received his B.Sc. degree from METU, Ankara, Turkey and his M.Sc. and Ph.D. degrees from Queen's University, Kingston, Ontario, Canada. His current research interests include cross-layer, spectrally efficient design of wireless air interfaces for multimedia services, adaptive resource allocation techniques, diversity techniques, relay networks, and peer-to-peer networks. He has authored numerous articles in these areas at refereed journals and international conferences and has over 25 issued and pending US and European patents. He has served and contributed in various telecommunications standards bodies on cdma2000, $1 \mathrm{xEV}-\mathrm{DO}$ and 1xEV-DV. Dr Sunay was a guest co-editor for the January 2000 issue of the IEEE Communications Magazine, titled "Telecommunications at the Start of the New Millennium" and served as the co-chair of the Wireless Communications Symposium at the IEEE ICC 2006 conference held in Istanbul. He was an Associate Editor for IEEE COMMUNICATIONS LETTERS in 2000-2005 and an Editor for IEEE TRANSACTIONS ON WIRELESS COMMUNICATIONS in 2004-2006. He is listed in Marquis Who is Who in the World and Who is Who in Engineering. 